\title{
Continuous measurement of air-water gas exchange by underwater eddy covariance
}

\author{
Peter Berg and Michael L. Pace \\ Department of Environmental Sciences, University of Virginia, Charlottesville, Virginia, USA \\ Correspondence to: Peter Berg (pb8n@virginia.edu)
}

Received: 1 August 2017 - Discussion started: 9 August 2017

Revised: 23 November 2017 - Accepted: 29 November 2017 - Published: 11 December 2017

\begin{abstract}
Exchange of gases, such as $\mathrm{O}_{2}, \mathrm{CO}_{2}$, and $\mathrm{CH}_{4}$, over the air-water interface is an important component in aquatic ecosystem studies, but exchange rates are typically measured or estimated with substantial uncertainties. This diminishes the precision of common ecosystem assessments associated with gas exchanges such as primary production, respiration, and greenhouse gas emission. Here, we used the aquatic eddy covariance technique - originally developed for benthic $\mathrm{O}_{2}$ flux measurements - right below the airwater interface $(\sim 4 \mathrm{~cm})$ to determine gas exchange rates and coefficients. Using an acoustic Doppler velocimeter and a fast-responding dual $\mathrm{O}_{2}$-temperature sensor mounted on a floating platform the 3-D water velocity, $\mathrm{O}_{2}$ concentration, and temperature were measured at high-speed $(64 \mathrm{~Hz})$. By combining these data, concurrent vertical fluxes of $\mathrm{O}_{2}$ and heat across the air-water interface were derived, and gas exchange coefficients were calculated from the former. Proofof-concept deployments at different river sites gave standard gas exchange coefficients $\left(k_{600}\right)$ in the range of published values. A $40 \mathrm{~h}$ long deployment revealed a distinct diurnal pattern in air-water exchange of $\mathrm{O}_{2}$ that was controlled largely by physical processes (e.g., diurnal variations in air temperature and associated air-water heat fluxes) and not by biological activity (primary production and respiration). This physical control of gas exchange can be prevalent in lotic systems and adds uncertainty to assessments of biological activity that are based on measured water column $\mathrm{O}_{2}$ concentration changes. For example, in the $40 \mathrm{~h}$ deployment, there was near-constant river flow and insignificant winds two main drivers of lotic gas exchange - but we found gas exchange coefficients that varied by several fold. This was presumably caused by the formation and erosion of vertical temperature-density gradients in the surface water driven by
\end{abstract}

the heat flux into or out of the river that affected the turbulent mixing. This effect is unaccounted for in widely used empirical correlations for gas exchange coefficients and is another source of uncertainty in gas exchange estimates. The aquatic eddy covariance technique allows studies of air-water gas exchange processes and their controls at an unparalleled level of detail.

A finding related to the new approach is that heat fluxes at the air-water interface can, contrary to those typically found in the benthic environment, be substantial and require correction of $\mathrm{O}_{2}$ sensor readings using high-speed parallel temperature measurements. Fast-responding $\mathrm{O}_{2}$ sensors are inherently sensitive to temperature changes, and if this correction is omitted, temperature fluctuations associated with the turbulent heat flux will mistakenly be recorded as $\mathrm{O}_{2}$ fluctuations and bias the $\mathrm{O}_{2}$ eddy flux calculation.

\section{Introduction}

\subsection{Background}

Exchange rates of gases over the air-water interface in rivers, streams, reservoirs, lakes, and estuaries are key parameters for estimating a number of important ecosystem variables (Cole et al., 2010). Gas exchange rates are used to estimate metabolism of aquatic systems (Hanson et al., 2004; Van de Bogert et al., 2007, 2012), emission of greenhouse gases like $\mathrm{CO}_{2}$ and $\mathrm{CH}_{4}$ to the atmosphere (Cole et al., 2010), and the role of inland and near-shore waters in regional (Billett and Moore, 2008) and global (Cole et al., 2007; Bastviken et al., 2011) carbon cycling. As a result, over several decades, a tremendous effort among aquatic scientists has focused 
on understanding and quantifying gas exchange processes at the air-water interface and their controls under naturally occurring field conditions (Whitman, 1923; Butman and Raymond, 2011; Raymond et al., 2013).

Multiple state variables and complex physical processes on both sides of the air-water interface control gas exchange (MacIntyre et al., 1995, 2010). Despite this complexity, the widely used expression for gas exchange rates was formulated based on a conceptually simple model assuming that gas is transported by molecular diffusion across intact boundary layers, or thin films, found on each side of the interface (Whitman, 1923; Liss and Slater, 1974):

$J_{\text {air-water }}=k\left(C_{\text {water }}-C_{\text {air }}\right)$,

where $J_{\text {air-water }}$ is the exchange rate, or vertical flux, of the gas (positive upward), $C_{\text {water }}$ is the gas bulk concentration below the film on the water side, $C_{\text {air }}$ is the concentration above the film on the air side, and $k$ is the gas exchange coefficient, often also referred to as the "gas transfer velocity" or "piston velocity". For most gases, $C_{\text {water }}$ and $C_{\text {air }}$ are straight forward to measure with modern sensors (Koopmans and Berg, 2015; Fritzsche et al., 2017), or calculate from known functions, but the complexity of gas exchange and its many controlling variables is contained in $k$ (MacIntyre et al., 1995; McKenna and McGillis, 2004; Cole et al., 2010).

For sparingly soluble gases such as $\mathrm{O}_{2}, \mathrm{CO}_{2}$, and $\mathrm{CH}_{4}$, the ratio between the molecular diffusivity in air and water is on the order of $10^{4}$. Consequently, the resistance to gas diffusion is associated with the film on the water side, even if a substantially thicker film is found on the air-side of the air-water interface. This means that in the case of $\mathrm{O}_{2}, C_{\text {air }}$ is simply the saturation concentration of $\mathrm{O}_{2}$ in water, which is a well-described function of the water temperature and salinity (Garcia and Gordon, 1992) and the atmospheric pressure.

Turbulence, or turbulent-like motions, that affects or controls the thickness of the film on the water side, and thus the diffusive resistance to gas transport, can be driven by conditions both below and above the air-water interface. In shallow streams and rivers, this turbulence is typically generated by the water flow over an uneven or rough bottom. Substantial heat loss from the water can similarly result in density-driven water motion that erodes the film (Bannerjee and MacIntyre, 2004). On the contrary, in reservoirs, lakes, and estuaries, the turbulence on the water side of the interface is typically generated by wind, which makes wind speed the dominant controlling variable for $k$ for such systems (Marino and Howarth, 1993). Despite the fact that typical conditions such as rough weather, surface waves, and rain can rupture the film on the water side, the simple expression for gas exchange (Eq. 1) is still applied with $k$ values that are adjusted accordingly (Watson et al., 1991). Keeping these multivariable, highly dynamic, and complex controls in mind, it is evident that determination of representative $k$ values for specific sites is a challenging task.

\subsection{Formulation of problem}

A number of approaches have been used to study and determine values for $k$. For smaller rivers and streams, they include targeted parallel up- and across-stream additions of volatile tracers (e.g., propane) and hydrologic tracers (e.g., dissolved chloride), where the latter is added to correct for dilution of propane due to hyporheic mixing (Genereux and Hemond, 1992; Koopmans and Berg, 2015). A common approach for smaller reservoirs and lakes relies on additions of inert tracers, e.g., $\mathrm{SF}_{6}$ (Wanninkhof, 1985; Cole et al., 2010), whereas floating chambers are often deployed in larger rivers, reservoirs, lakes, and estuaries (Marino and Howarth, 1993). In a limited number of studies of large reservoirs and lakes, tower-mounted atmospheric eddy covariance systems have been used to measure air-water exchange, and from that, $k$ values were derived (Anderson et al., 1999; Jonsson et al., 2008; Mammarella et al., 2015). Partly motivated by the substantial and often methodologically challenging effort required to measure $k$ at specific sites with any of these approaches, many studies have simply relied on general empirical correlations for $k$ produced by fitting $k$ values measured for other similar aquatic systems (Raymond and Cole, 2001; Borges et al., 2004; Cole et al., 2010). With the exception of atmospheric eddy covariance measurements, none of these approaches represent a direct way of determining $k$ values because they rely on assumptions that often are difficult to assess, or simply not fulfilled. As a result, gas exchange is viewed among aquatic scientists as the primary source of uncertainty in many standard estimates for aquatic systems such as gross primary production, respiration, and net ecosystem metabolism (Wanninkhof et al., 1990; Raymond and Cole, 2001; Raymond et al., 2012).

\subsection{Scope of work}

The aquatic eddy covariance technique for $\mathrm{O}_{2}$ flux measurements under undisturbed in situ conditions was originally developed for the benthic environment (Berg et al., 2003). The approach has several significant advantages over other flux methods, including its non-invasive nature (Lorrai et al., 2010), high temporal resolution (Rheuban and Berg, 2013), and its ability to integrate over a large benthic surface (Berg et al., 2007). As a result, it has been used to measure wholesystem fluxes for substrates such as river bottoms (Lorke et al., 2012; Berg et al., 2013), seagrass meadows (Hume et al., 2011; Rheuban et al., 2014), and coral reefs (Long et al., 2013; Rovelli et al., 2015).

Here, we applied the aquatic eddy covariance technique "upside down" right below the air-water interface to measure $\mathrm{O}_{2}$ fluxes. From these fluxes, we derived exchange coefficients for $\mathrm{O}_{2}$, and then standard gas exchange coefficients $\left(k_{600}\right)$. All measurements were done from a floating platform, and because we used a newly developed fast-responding dual $\mathrm{O}_{2}$-temperature sensor (Berg et al., 2016), we were able to 
derive parallel fluxes of $\mathrm{O}_{2}$ and thermal energy, or sensible heat. We conducted proof-of-concept tests that were up to $40 \mathrm{~h}$ long at three river sites.

\section{Methods}

\subsection{Floating measurements platform}

All measurements were made from a $1.2 \mathrm{~m} \times 0.9 \mathrm{~m}$ floating platform with a catamaran-shaped hull (Fig. 1) that was kept at a fixed position at the river sites by two upstream anchors. The modular design and the catamaran-shaped hull allow the platform to be collapsed for storage and easy shipment in a standard sturdy polymer case (Pelican Products, USA).

The 3-D velocity field was measured with an acoustic Doppler velocimeter (ADV) with a cabled sensor head (cabled Vector, Nortek AS, Norway). This type of ADV allowed the sensor head to be positioned facing upwards (Fig. 1) while recording the velocity field right below the air-water interface (typically $\sim 4 \mathrm{~cm}$ ). This distance was determined from standard ADV output. Data were collected continuously at a rate of $64 \mathrm{~Hz}$ and represent water velocity values averaged over the ADV's cylindrical measuring volume $(h \sim 1.4 \mathrm{~cm}, \emptyset \sim 1.4 \mathrm{~cm})$ located $15.7 \mathrm{~cm}$ above the sensor head (Fig. 1).

The $\mathrm{O}_{2}$ concentration was measured with a new fastresponding dual $\mathrm{O}_{2}$-temperature sensor (RINKO EC, JFE Advantech, Japan) developed specifically for eddy covariance measurements (Berg et al., 2016). This sensor allows for deriving simultaneous fluxes of $\mathrm{O}_{2}$ and heat. It also allows instantaneous temperature correction of the $\mathrm{O}_{2}$ concentration. The sensor was designed to interface with our standard ADVs (Vector, Nortek AS, Norway) through a single cable supplying power to the sensor and also transmitting its two outputs, one for $\mathrm{O}_{2}$ and one for temperature, to the ADV's data logger to be recorded along with velocities to ensure perfect time alignment of all data. The $\mathrm{O}_{2}$ measuring part of this new sensor is a small $6 \mathrm{~mm}$ diameter planar optode and concentrations are determined from fluorescence life-time measurements (Klimant et al., 1995; Holst et al., 1997, 1998). The tip of the sensor, which contains both the temperature thermistor and the $\mathrm{O}_{2}$ sensing foil, has a diameter of $8.0 \mathrm{~mm}$, which makes it far more robust than $\mathrm{O}_{2}$ microsensors typically used for aquatic eddy covariance measurements. Yet because the sensor's tip is still only half the size of the ADV's measuring volume, it will not limit the eddy size that can be measured by the system. The sensor's response times $\left(t_{90} \%\right)$ were measured to be $0.51 \pm 0.01 \mathrm{~s}$ ( $\mathrm{SE}, n=7$ ) for $\mathrm{O}_{2}$ and $0.34 \pm 0.01 \mathrm{~s}$ (SE, $n=9$ ) for temperature (Berg et al., 2016). The same response time for $\mathrm{O}_{2}$ was consistently found when the $\mathrm{O}_{2}$ sensing foil was replaced (an easy user performed operation typically needed after $\sim 10$ days of continuous use). The edge of the sensor tip was positioned $\sim 2.0 \mathrm{~cm}$ downstream of the edge of the ADV's measuring volume so that water passed through this volume before sweeping over the angled $\mathrm{O}_{2}$ sensing tip (Fig. 1a). This setup ensured undisturbed measurements of the natural current flow. Power was supplied from an external battery (Fig. 1a) with a capacity that allowed $64 \mathrm{~Hz}$ data to be collected continuously for at least $48 \mathrm{~h}$. Because all instrument components were designed for underwater use they were not affected by rain or humid conditions.

Measurement of supporting environmental variables during each deployment allowed verification of recorded data and assisted in the interpretation of the derived eddy fluxes. These variables included mean $\mathrm{O}_{2}$ concentration and temperature at the measuring depth recorded every $1 \mathrm{~min}$ with one or two stable independent dual $\mathrm{O}_{2}$-temperature sensors (miniDOT, PME, USA; referred to as the independent sensor below). In most deployments, photosynthetically active radiation (PAR) was recorded at the measuring depth every $5 \mathrm{~min}$ using an independent submersible PAR sensor (Odyssey, Dataflow Systems, New Zealand). For one deployment, light data were used from nearby meteorological weather stations.

\subsection{Field tests}

The new approach for determining air-water gas exchange rates and associated exchange coefficients from underwater eddy covariance measurements was tested at three river sites, all in Virginia (US); one in the Hardware River, one in the Mechums River, and one in the Moormans River. All sites had a fairly linear run with a water depth between $\sim 0.3$ and $\sim 1 \mathrm{~m}$ and smooth and quietly flowing water without standing riffles or waves. As a result of this, the twopoint anchoring system, and the current's constant pull on the hull, the platform was stationary during measurements. Typical surface flow velocities ranged from 6 to $30 \mathrm{~cm} \mathrm{~s}^{-1}$. The $\mathrm{ADV}$ and the fast-responding $\mathrm{O}_{2}$-temperature sensor were adjusted to record data $\sim 4 \mathrm{~cm}$ below the air-water interface. Four deployments lasting up to $40 \mathrm{~h}$ were initiated on 22 November 2015 and 14 September 2016 in the Hardware River, on 21 December 2016 in the Mechums River, and on 18 January 2017 in the Moormans River. Using a level and by placing dive weights on the platform (Fig. 1b) care was taken to ensure that the platform was horizontal within the tolerance of the level to minimize post-processing rotations of the velocity field to correct for sensor tilt.

\subsection{Calculations of eddy fluxes}

Fluxes of $\mathrm{O}_{2}$ were extracted from the raw eddy covariance data following the multi-step process briefly described below.

Using the two simultaneously measured outputs from the fast-responding dual $\mathrm{O}_{2}$-temperature sensor, one for $\mathrm{O}_{2}$ and one for temperature, the $\mathrm{O}_{2}$ concentration was calculated from the calibration equation provided by the manufacturer. Because this equation contains both outputs, this calculation includes instantaneous temperature correction of the $\mathrm{O}_{2}$ 


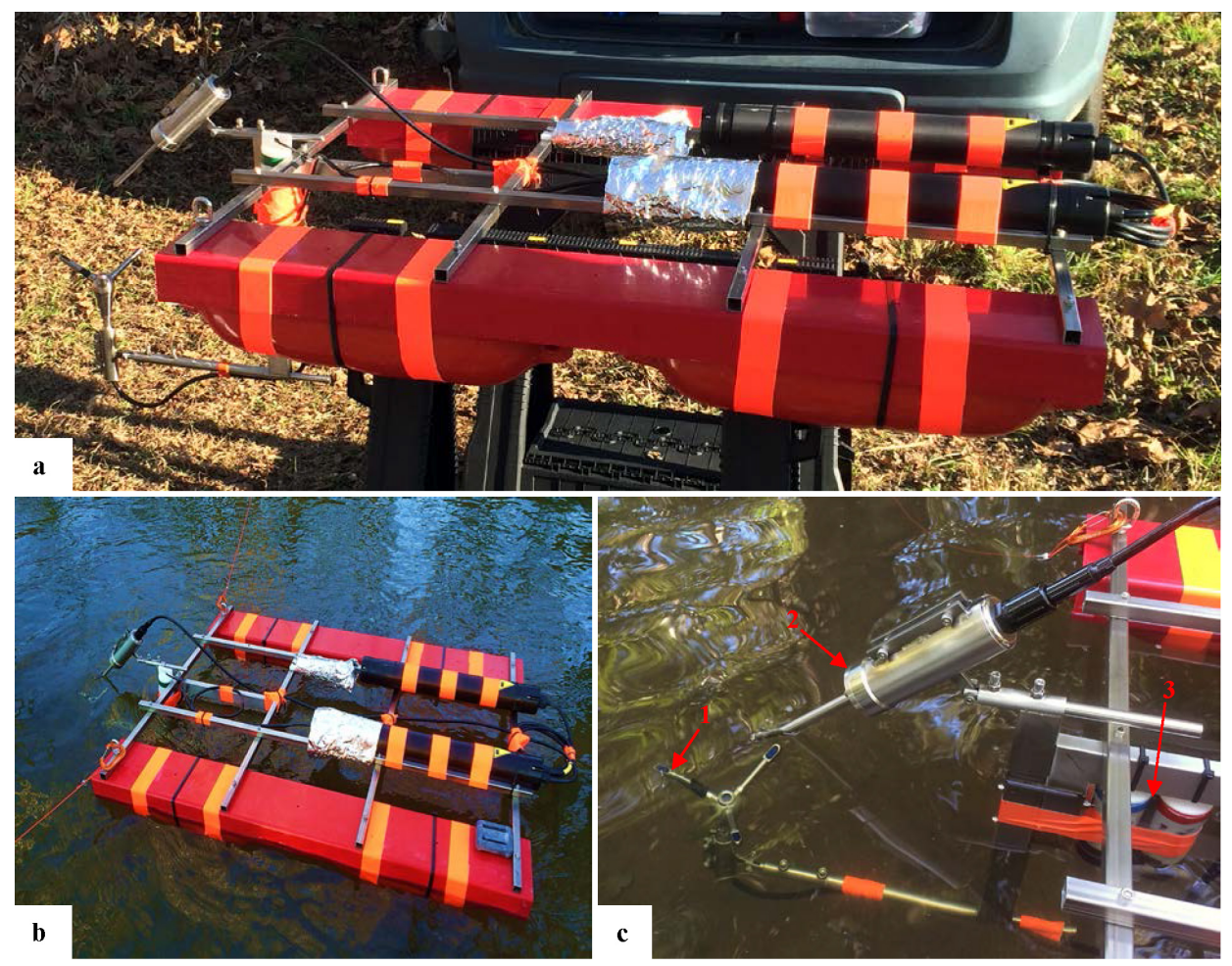

Figure 1. Floating platform for determining air-water gas exchange. (a) The $1.2 \mathrm{~m} \times 0.9 \mathrm{~m}$ wide platform with a catamaran-shaped hull being prepared for deployment. Four inflatable fenders provide flotation. (b) The platform deployed in the Hardware River and anchored to both river banks. A dive weight is used to level the platform. (c) Close-up look at: (1) the three-pronged upward-facing sensor head of the cabled acoustic Doppler velocimeter (cabled Vector, Nortek AS, Norway), (2) the fast-responding dual $\mathrm{O}_{2}$-temperature sensor (RINKO EC, JFE Advantech, Japan), and (3) two stable independent dual $\mathrm{O}_{2}$-temperature sensors used for calibration (miniDOT, PME, USA).

concentration evaluated in detail below. If needed, the $\mathrm{O}_{2}$ concentration was calibrated against the independent sensor data. All $64 \mathrm{~Hz}$ data were then reduced to $8 \mathrm{~Hz}$ data, which reduces noise while providing sufficient resolution to contain the full frequency spectrum carrying the detectable flux signal (Berg et al., 2009). This assumption was validated by comparing fluxes calculated from both 8 and $64 \mathrm{~Hz}$ data for a subset of the data.

$\mathrm{O}_{2}$ fluxes, one for each $15 \mathrm{~min}$ data segment, were extracted from the $8 \mathrm{~Hz}$ data using the software package EddyFlux version 3.1 (P. Berg, unpublished data). If needed, this software rotates the flow velocity field for each data segment to correct for any sensor tilt (Lee et al., 2004; Lorrai et al., 2010; Lorke et al., 2013) bringing the transverse and vertical mean velocities to zero. The vertical eddy flux was then calculated as (defined positive upward)

$J_{\text {eddy }}=\overline{w^{\prime} C^{\prime}}$,

where the overbar symbolizes averaging over the $15 \mathrm{~min}$ data segment, and $w^{\prime}$ and $C^{\prime}$ are the fluctuating vertical velocity and the fluctuating $\mathrm{O}_{2}$ concentration, respectively. These fluctuating components were calculated as $w-\bar{w}$ and $C-\bar{C}$ where $w$ and $C$ are measured values (at $8 \mathrm{~Hz}$ ), and $\bar{w}$ and $\bar{C}$ are mean values defined as least square linear fits to all $w$ and
$C$ values within the $15 \mathrm{~min}$ time segment, a procedure usually referred to as linear de-trending (Lee et al., 2004; Berg et al., 2009).

Due to the response time of the dual $\mathrm{O}_{2}$-temperature sensor and its position downstream from the ADV's measuring volume, a time shift correction was applied. This was done by repeating the outlined flux calculation, while shifting the $8 \mathrm{~Hz} \mathrm{O}_{2}$ concentration data back in time, $0.125 \mathrm{~s}(1 / 8 \mathrm{~s})$ at a time, until the numerically largest flux was found.

Estimating the gas exchange coefficient requires the $\mathrm{O}_{2}$ flux over the air-water interface to be known. However, the eddy flux, $J_{\text {eddy }}$ (Eq. 2 ), is measured $\sim 4 \mathrm{~cm}$ below the interface. By using the linear fit to the measured $\mathrm{O}_{2}$ concentrations in each 15 min data segment, defined as $\bar{C}$ above, $J_{\text {eddy }}$ is corrected for storage of $\mathrm{O}_{2}$ in the $\sim 4 \mathrm{~cm}$ column of water to give the flux at the air-water interface:

$J_{\text {eddy, air-water }}=J_{\text {eddy }}-\int_{0}^{h} \frac{\mathrm{d} \bar{C}}{\mathrm{~d} t} \mathrm{~d} z$,

where $h$ is the $\sim 4 \mathrm{~cm}$ tall water column, and the integral represents the change in time of $\mathrm{O}_{2}$ stored in this column. For further details on this flux extraction protocol included in EddyFlux version 3.1, see Lorrai et al. (2010), Hume et 

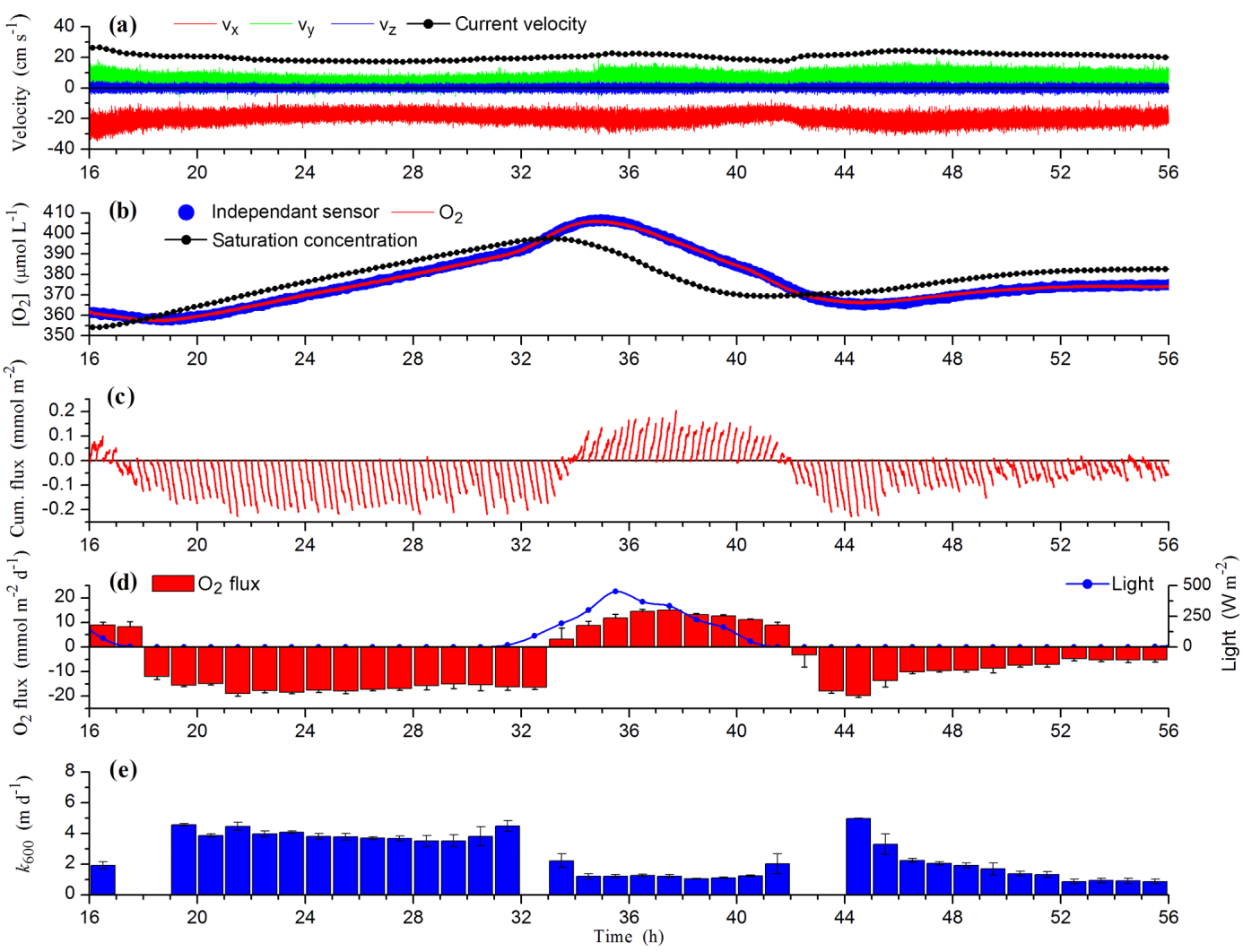

Figure 2. A $40 \mathrm{~h}$ long test deployment initiated at 16:00 LT in the afternoon as indicated on the $x$ axis. (a) Three velocity components at $8 \mathrm{~Hz}\left(x, y, z ; z\right.$ is vertical) and 15 min mean current velocity. (b) $\mathrm{O}_{2}$ concentration at $8 \mathrm{~Hz}$ measured with the dual $\mathrm{O}_{2}$-temperature sensor and at 1 min measured with an independent sensor. (c) Cumulative flux over 15 min time intervals with clear linear trends. (d) Hourly $\mathrm{O}_{2}$ flux (positive values represent a release from the river), each value based on 15 min flux extractions $(n=4$, SE) and day light measured at a nearby weather station. (e) Hourly standard gas exchange coefficient $\left(k_{600}\right)$ based on 15 min estimates $(n=4$, SE). The few gaps in the data are for the times when the driving $\mathrm{O}_{2}$ concentration difference changes sign (c).

al. (2011), and Rheuban et al. (2014). For presentation, the 15 min fluxes were lumped in groups of four to give hourly values.

To examine the eddy frequencies that carried the flux signal, cumulative co-spectra of the $\mathrm{O}_{2}$ concentration and the vertical velocity were calculated for representative periods in each deployment using the software package Spectra version 1.2 (P. Berg, unpublished data). This software essentially performs the identical flux calculation in the frequency domain after fast Fourier transforming the de-trended data as EddyFlux does in the time domain. Both software packages rely on the same methods for de-trending and time shifting data.

Heat fluxes and associated co-spectra were extracted from the raw eddy covariance data following the same multi-step process.

\subsection{Calculations of gas exchange coefficients}

The saturation concentration of $\mathrm{O}_{2}\left(C_{\text {air }}\right.$ in Eq. 1) was calculated from Garcia and Gordon (1992) as a function of salinity (here $0 \%$ ) and surface water temperature measured with the fast-responding dual $\mathrm{O}_{2}$-temperature sensor $\sim 4 \mathrm{~cm}$ below the air-water interface and then corrected for actual atmospheric pressure (average sea-level pressure of $1013.25 \mathrm{mbar}$ corrected for elevation). The water column $\mathrm{O}_{2}$ bulk concentration ( $C_{\text {water }}$ in Eq. 1) was measured with the same sensor. By substituting $J_{\text {air-water }}$ (Eq. 1) with the 15 min values for $J_{\text {eddy, air-water }}$ (Eq. 3), a gas exchange coefficient for $\mathrm{O}_{2}$ was calculated from Eq. (1) and converted to the standard exchange coefficient, $k_{600}$, for $\mathrm{CO}_{2}$ at $20^{\circ} \mathrm{C}$ (Cole et al., 2010). For presentation, the $15 \mathrm{~min} k_{600}$ values were lumped in groups of four to give hourly values.

\section{Results}

All four deployments resulted in high-quality time series of the velocity field, the $\mathrm{O}_{2}$ concentration, and the temperature $\sim 4 \mathrm{~cm}$ below the air-water interface, and derived from those, air-water fluxes of $\mathrm{O}_{2}$ and heat, and gas exchange coefficients. These data and their interpretation are presented below. 


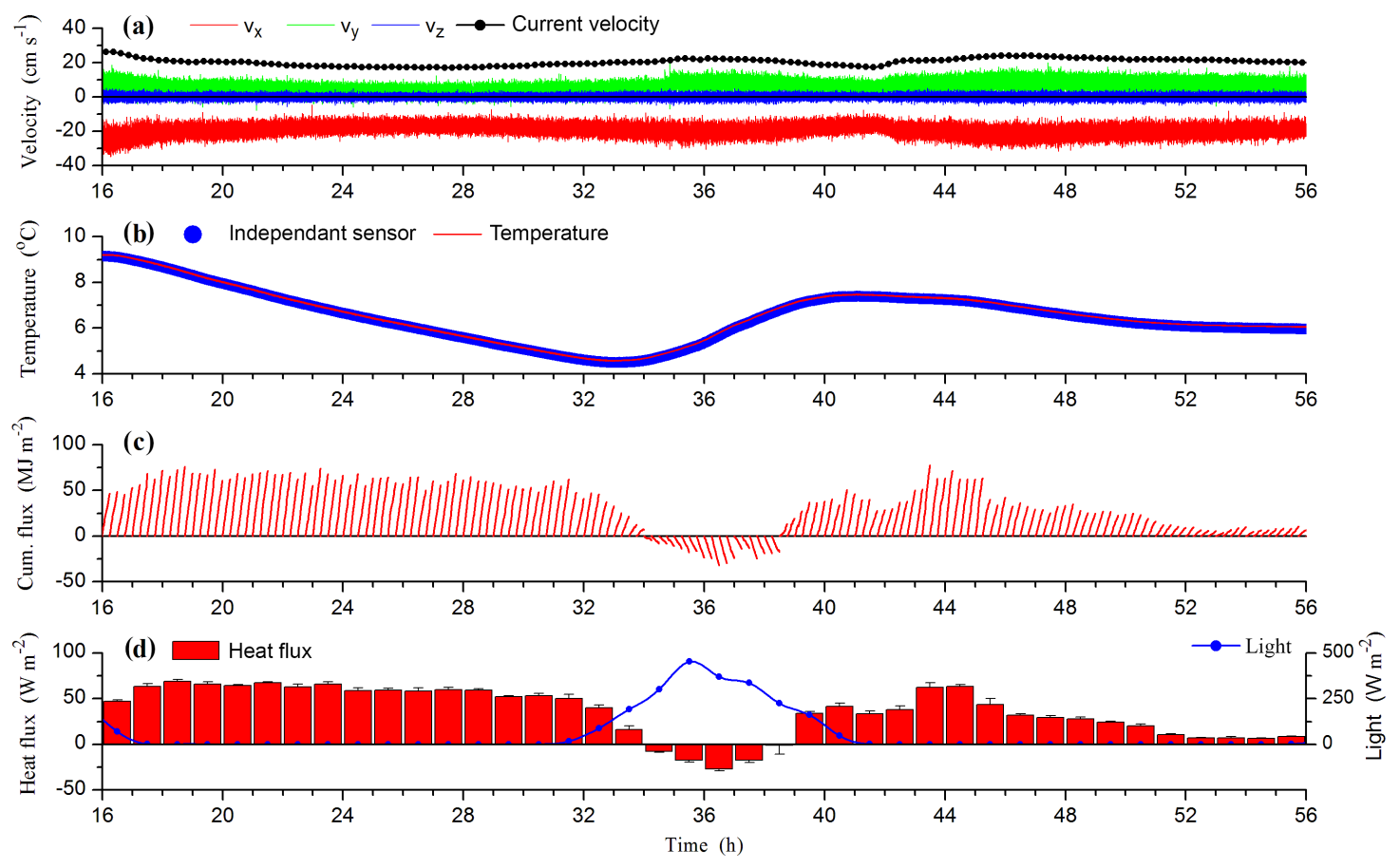

Figure 3. The same deployment as in Fig. 2, but with results for temperature and heat. The deployment was initiated at 16:00 LT in the afternoon as indicated on the $x$ axis. (a) Three velocity components at $8 \mathrm{~Hz}(x, y, z ; z$ is vertical) and 15 min mean current velocity. (b) Temperature at $8 \mathrm{~Hz}$ measured with the dual $\mathrm{O}_{2}$-temperature sensor and at 1 min measured with an independent sensor. (c) Cumulative flux over 15 min time intervals with clear linear trends. (d) Hourly heat flux, each value based on 15 min flux extractions $(n=4$, SE) and day light measured at a nearby weather station. Positive flux values represent a release of heat from the river.

\subsection{Data example}

For a $40 \mathrm{~h}$ long deployment initiated on 18 January 2017 in the Moormans River, the 15 min mean current velocity (Fig. 2a) was relatively constant (averaging $20.5 \mathrm{~cm} \mathrm{~s}^{-1}$ ). The $\mathrm{O}_{2}$ concentration measured with the fast-responding dual $\mathrm{O}_{2}$-temperature sensor (Fig. 2b) agreed closely with the concentration recorded with the independent sensor and showed a distinct diurnal pattern. During most of the first night of the deployment, the $\mathrm{O}_{2}$ concentration increased linearly (h 19 to h 32), whereas a smaller and non-linear increase that tapered off was measured during the second night (h 45 to h 56). A diurnal pattern was also seen in the calculated $\mathrm{O}_{2}$ saturation concentration (Fig. 2b) reflecting variation in water temperature. The cumulative $\mathrm{O}_{2}$ flux (Fig. 2c), with each data segment covering a $15 \mathrm{~min}$ time interval, had clear linear trends indicating a strong eddy flux signal in the data. The hourly $\mathrm{O}_{2}$ flux (Fig. 2d), representing means of four successive 15 min flux estimates, also exhibited a clear diurnal pattern with a nighttime average uptake by the river of $16.4 \mathrm{mmol} \mathrm{m}^{-2} \mathrm{~d}^{-1}$ for the first night, $9.1 \mathrm{mmol} \mathrm{m}^{-2} \mathrm{~d}^{-1}$ for the second night, and an average daytime release of $11.1 \mathrm{mmol} \mathrm{m}^{-2} \mathrm{~d}^{-1}$. As observed for the $\mathrm{O}_{2}$ concentration (Fig. 2b), the hourly $\mathrm{O}_{2}$ flux differed during the two nighttime periods with a near-constant flux during the first night and a flux that tapered off during the second night. The hourly standard gas exchange coefficient $\left(k_{600} ;\right.$ Fig. 2e) derived from the $15 \mathrm{~min} \mathrm{O}_{2}$ flux and the $\mathrm{O}_{2}$ concentration difference over the air-water interface (Fig. 2b) was almost constant over the first night of the deployment with an average of $3.9 \mathrm{~m} \mathrm{~d}^{-1}$. After that, $k_{600}$ diminished almost 3-fold to a value of $1.4 \mathrm{~m} \mathrm{~d}^{-1}$ during the daytime. During the second night, $k_{600}$ tapered off markedly from a level found for the first night to almost $0.89 \mathrm{md}^{-1}$ during the last $4 \mathrm{~h}$ of the deployment. This pattern was unexpected given the almost constant mean current velocity (Fig. 2a) and insignificant winds and the similar $\mathrm{O}_{2}$ concentration difference (Fig. 2b) for the two nighttime periods. The pattern suggests that gas exchange was controlled by at least one driver apart from the river current velocity or winds (see Discussion section below).

The parallel temperature data measured with the fastresponding dual $\mathrm{O}_{2}$-temperature sensor agreed perfectly with the temperature recorded with the independent sensor (Fig. 3b) and had, as with the $\mathrm{O}_{2}$ concentration, a distinct diurnal pattern. A near-linear decrease occurred during the first night (h 18 to h 32), whereas a smaller and non-linear decrease that tapered off was recorded during the second night (h 45 to h 56). During the daytime the temperature increased. Unfortunately, we do not have reliable on-site measurements of the air temperature, but we infer that it, together with short-wave (sunlight during day) and long-wave (nighttime) 


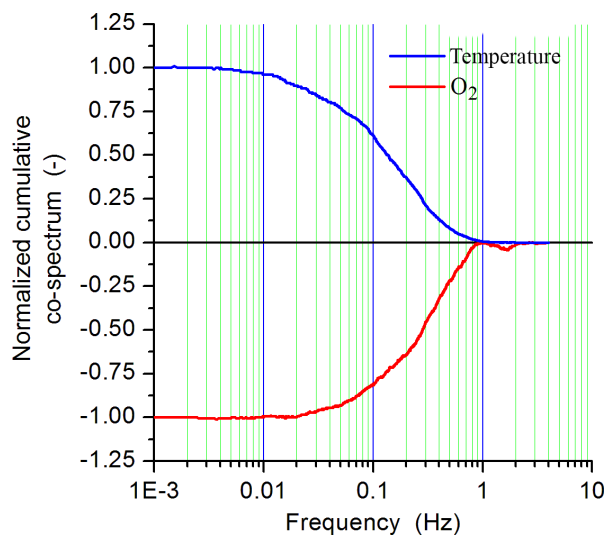

Figure 4. Nighttime normalized cumulative co-spectra for the vertical velocity combined with the $\mathrm{O}_{2}$ concentration and the temperature, respectively, revealing which frequencies carried the eddy flux signal.

thermal radiation, controlled the recorded water temperature variations (Fig. 3b). The cumulative heat flux (Fig. 3c) had, as for $\mathrm{O}_{2}$, clear linear trends indicating a strong flux signal in the data. The hourly heat flux (Fig. 3d) also exhibited a clear diurnal pattern with a nighttime average release of heat of $60.6 \mathrm{~W} \mathrm{~m}^{-2}$ for the first night and $27.5 \mathrm{~W} \mathrm{~m}^{-2}$ for the second night. As was observed for the temperature (Fig. 3b), the hourly heat flux showed different trends for the two nights with a near-constant flux during the first night and a flux that tapered off during the second night.

Ignoring differences in the sign, representative cumulative co-spectra for the $\mathrm{O}_{2}$ and heat fluxes (Fig. 4) during the first night (Figs. 2, 3) were similar in the 0.1 to $1 \mathrm{~Hz}$ frequency band with all substantial flux contributions for both the $\mathrm{O}_{2}$ and heat fluxes having frequencies lower than $\sim 0.9 \mathrm{~Hz}$.

Due to careful leveling of the platform prior to data collection (Fig. 1b), rotation of the velocity field to correct for sensor tilt was minimal with an average of only $1.3^{\circ}$ from horizontal. This rotation had an insignificant effect on the flux calculation. The applied time shift averaged 1.3 and $1.2 \mathrm{~s}$ for the $\mathrm{O}_{2}$ and heat flux calculations, respectively, whereas the average storage correction (Eq. 3) amounted to $11 \%$ for the $\mathrm{O}_{2}$ flux and $15 \%$ for the heat flux.

\subsection{Representative gas exchange coefficients}

The three other test deployments were shorter than the one presented in Figs. 2 and 3 but results were of comparable quality. Average values for selected parameters covering periods of time with several successive $15 \mathrm{~min}$ time intervals from all four deployments are given in Table 1. These periods were identified by containing consecutive time intervals with consistent standard gas exchange coefficient values, $k_{600}$, that had little variation and appeared to represent a particular field condition. The longest period $(n=51)$ covers the first full night of the deployment shown in Fig. 2 (h 19 to

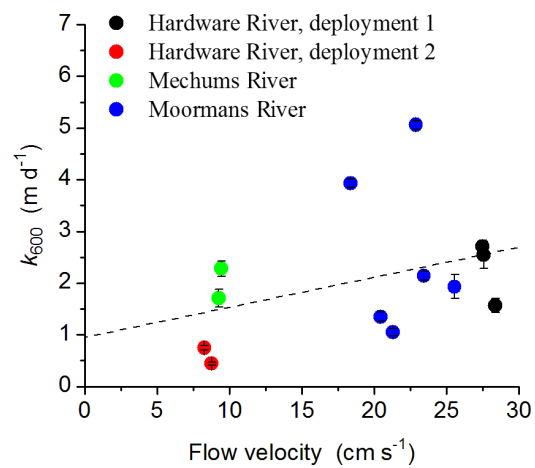

Figure 5. Standard gas exchange coefficient, $k_{600}$, plotted against river current velocity. The dotted line is a linear fit to all data $(R=$ $0.37, p=0.22$ ).

h 32). Overall, the average current velocity varied from 8.3 to $28.4 \mathrm{~cm} \mathrm{~s}^{-1}$ while $k_{600}$ ranged from 0.4 to $5.1 \mathrm{~m} \mathrm{~d}^{-1}$, or more than a factor of 12 .

There was no significant relationship $(R=0.37, p=$ 0.22 ) between river current velocity and $k_{600}$ values (Fig. 5) for all of the data in Table 1 . Substantial variations in $k_{600}$ values were found for some individual deployments even though the current velocity did not change markedly. Most prominently in the Moormans River deployment (Figs. 2, 3), where the $k_{600}$ values varied more than a factor of 5 . As we discuss below, this suggest that, at least for some sites and under some field conditions, other drivers of air-water gas exchange than river flow and winds are more important.

\subsection{Temperature effects on $\mathrm{O}_{2}$ readings - a possible methodological bias}

In the benthic environment the vertical turbulent heat flux is usually small relative to the $\mathrm{O}_{2}$ flux due to slowly and modestly varying mean temperatures in the bottom water. At the air-water interface, however, the heat flux is typically larger due to substantial variations in air temperature and shortand long-wave thermal radiation, and the associated turbulent temperature fluctuations can represent a challenge in $\mathrm{O}_{2}$ flux measurements by eddy covariance.

All highly sensitive fast-responding $\mathrm{O}_{2}$ sensors that can be used for aquatic eddy covariance measurements are to the best of our knowledge inherently sensitive to temperature changes, and thus give variable $\mathrm{O}_{2}$ readings at the same molar $\mathrm{O}_{2}$ concentration if the temperature varies. Typical temperature coefficients (\% change in $\mathrm{O}_{2}$ concentration reading caused by a temperature change of $1^{\circ} \mathrm{C}$ ) for Clark-type microelectrodes, the most common sensor type used for aquatic eddy covariance, have values of $\sim 3 \%$ (Gundersen et al., 1998). Lab measurements in which the $\mathrm{O}_{2}$ concentration was held constant but temperature varied showed that the fastresponding dual $\mathrm{O}_{2}$-temperature sensor used in this study has a temperature coefficient of $2.9 \%$ if temperature correc- 
Table 1. Representative standard gas exchange coefficients $\left(k_{600}\right)$ along with current velocity and $\mathrm{O}_{2}$ flux for four deployments at three different sites. The third column $(n)$ specifies the number of $15 \mathrm{~min}$ time intervals included in the averages. Values from the last deployment (Moormans River) are depicted in Figs. 2 and 3.

\begin{tabular}{|c|c|c|c|c|c|}
\hline $\begin{array}{l}\text { Deployment } \\
\text { - }\end{array}$ & $\begin{array}{l}\text { Start date } \\
-\end{array}$ & $\begin{array}{l}n \\
-\end{array}$ & $\begin{array}{r}\text { Current velocity } \\
\mathrm{cm} \mathrm{s}^{-1}\end{array}$ & $\begin{array}{r}\mathrm{O}_{2} \text { flux } \\
\text { mmol m}{ }^{-2} \mathrm{~d}^{-1}\end{array}$ & $\begin{array}{r}k_{600} \\
\mathrm{~m} \mathrm{~d}^{-1}\end{array}$ \\
\hline Hardware River, deployment 1 & 22 Nov 2015 & 20 & 28.4 & 9.1 & 1.6 \\
\hline Hardware River, deployment 1 & 22 Nov 2015 & 39 & 27.5 & 12.0 & 2.7 \\
\hline Hardware River, deployment 1 & 22 Nov 2015 & 13 & 27.6 & -10.7 & 2.5 \\
\hline Hardware River, deployment 2 & 14 Sep 2016 & 20 & 8.7 & 7.0 & 0.4 \\
\hline Hardware River, deployment 2 & 14 Sep 2016 & 4 & 8.3 & 9.4 & 0.7 \\
\hline Mechums River & 21 Dec 2016 & 23 & 9.4 & -42.9 & 2.3 \\
\hline Mechums River & 21 Dec 2016 & 36 & 9.3 & -29.2 & 1.7 \\
\hline Moormans River & 18 Jan 2017 & 4 & 25.6 & -8.9 & 1.9 \\
\hline Moormans River & 18 Jan 2017 & 51 & 18.4 & 16.8 & 3.9 \\
\hline Moormans River & 18 Jan 2017 & 34 & 20.4 & -11.8 & 1.3 \\
\hline Moormans River & 18 Jan 2017 & 3 & 22.9 & 19.3 & 5.1 \\
\hline Moormans River & 18 Jan 2017 & 16 & 23.4 & 10.1 & 2.1 \\
\hline Moormans River & 18 Jan 2017 & 26 & 21.3 & 5.8 & 1.0 \\
\hline
\end{tabular}

tion was omitted. This characteristic of fast-responding $\mathrm{O}_{2}$ sensors implies that rapid temperature fluctuations associated with any turbulent heat flux will mistakenly be recorded as fluctuations in $\mathrm{O}_{2}$ concentration and bias the $\mathrm{O}_{2}$ flux calculation unless an instantaneous temperature correction of the signal is performed. In this study, this correction was done using the fast-responding dual $\mathrm{O}_{2}$-temperature sensor's temperature reading from within a few millimeters of the $\mathrm{O}_{2}$ sensing foil. Below, we exemplify the nature and magnitude of this potential bias using data measured during the first night (h 18 to h 32) of the deployment shown in Figs. 2 and 3.

The turbulent temperature fluctuations for a $3 \mathrm{~min}$ period shown in Fig. 6a are associated with a vertical heat flux of $\sim 60 \mathrm{~W} \mathrm{~m}^{-2}$ (Fig. $3 \mathrm{~d}$ ) and amount to $\pm \sim 0.015^{\circ} \mathrm{C}$. Based on a temperature coefficient of $\sim 3 \%$, this translates into fluctuations in $\mathrm{O}_{2}$ concentration readings of $\pm \sim 0.2 \mu \mathrm{mol} \mathrm{L}^{-1}$ (Fig. 6a; right axis). Using such "simulated" $\mathrm{O}_{2}$ data, derived from the $8 \mathrm{~Hz}$ nighttime temperature data (Fig. 3; h 18 to $\mathrm{h} 32$ ), representing solely temperature sensitivity effects and no true $\mathrm{O}_{2}$ reading, produced an $\mathrm{O}_{2}$ release, or flux bias, of $11.9 \mathrm{mmol} \mathrm{m}^{-2} \mathrm{~d}^{-1}$ (blue bar; Fig. 6b). Using the instantaneous temperature corrected $\mathrm{O}_{2}$ data, as was done for all other calculations we present, gives an oppositely directed $\mathrm{O}_{2}$ uptake of $16.9 \mathrm{mmol} \mathrm{m}^{-2} \mathrm{~d}^{-1}$ (red bar; Fig. 6b). Using the sensor's $\mathrm{O}_{2}$ readings, but without the instantaneous temperature correction, gives an update of only $4.4 \mathrm{mmol} \mathrm{m}^{-2}$ $\mathrm{d}^{-1}$ (green bar; Fig. 6b).

The magnitude of this $\mathrm{O}_{2}$ flux bias, if temperature correction is omitted, scales with the heat flux and is proportional to the $\mathrm{O}_{2}$ sensor's temperature coefficient and the actual $\mathrm{O}_{2}$ concentration. Given the millimeter-close proximity of the temperature thermistor and the $\mathrm{O}_{2}$ sensing foil, and the relatively small difference between the fast-responding dual $\mathrm{O}_{2}$-temperature sensor's response times $\left(0.51\right.$ for $\mathrm{O}_{2}$ and $0.34 \mathrm{~s}$ for temperature; Berg et al., 2016), we conclude that the effects of temperature sensitivity were removed from our $\mathrm{O}_{2}$ flux calculations. This point is supported by the highfrequency end $(\sim 0.9 \mathrm{~Hz})$ of the co-spectra for the $\mathrm{O}_{2}$ and heat fluxes (Fig. 4).

\section{Discussion}

Deploying the aquatic eddy covariance technique right below the air-water interface provided a feasible way to determine gas exchange rates and coefficients. Relative to what is possible with traditional methods, this new approach gives gas exchange rates and coefficients with an improved precision and at a higher spatial and temporal resolution. For those reasons, the approach has the potential to enhance our knowledge of the dynamics and controls of gas exchange and thus benefit aquatic ecosystem studies and pave the way for new lines of ecosystem research.

These points are exemplified in our longest test deployment that lasted $40 \mathrm{~h}$ (Figs. 2, 3) and resulted in aquatic eddy covariance data for both $\mathrm{O}_{2}$ and temperature of a quality and internal consistency that fully match those published for many benthic environments (see review by Berg et al., 2017). Specifically, the $8 \mathrm{~Hz}$ velocity, $\mathrm{O}_{2}$, and temperature data (Figs. 2a, b, 3b) were recorded with low noise and the $\mathrm{O}_{2}$ and temperature data perfectly matched measurements with the stable independent sensor (Figs. 2b, 3b). Furthermore, the cumulative fluxes (Figs. 2c, 3c) had clear linear trends that indicate a strong and consistent flux signal in the data, and the times when the hourly $\mathrm{O}_{2}$ flux changed direction (Fig. 2d; positive values represent a release), matched exactly the times when the driving $\mathrm{O}_{2}$ concentration difference changed sign (Fig. 2b). Moreover, the cumulative co-spectra 

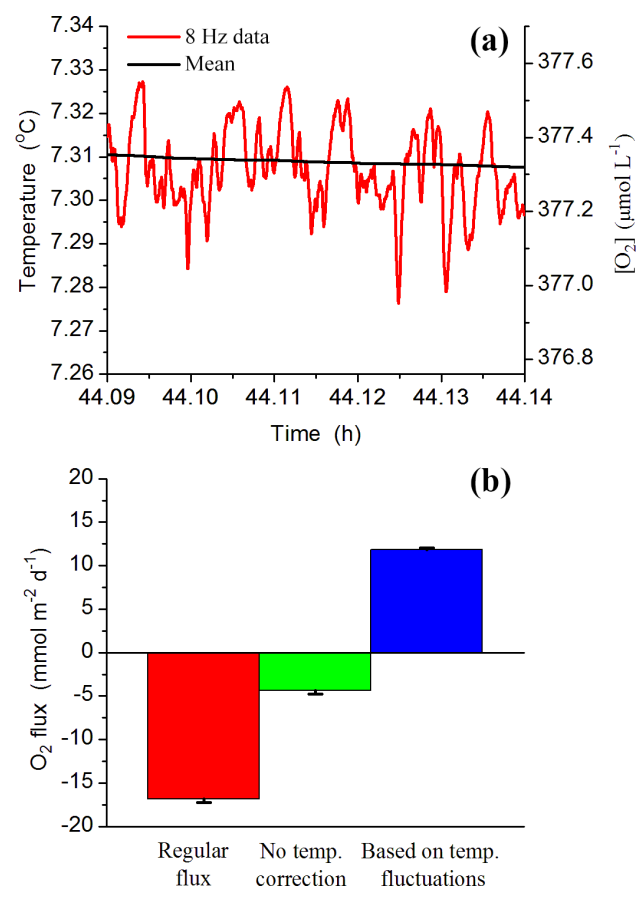

Figure 6. Bias that can arise if $\mathrm{O}_{2}$ concentration sensor readings are not corrected using rapid parallel temperature measurements. (a) Recorded $8 \mathrm{~Hz}$ data of temperature fluctuations and their mean (left axis) through $3 \mathrm{~min}$ and the resulting fluctuations in $\mathrm{O}_{2}$ concentration that would be recorded solely due to temperature sensitivity by a sensor with a temperature coefficient of $3 \%$ (right axis). (b) Average air-water $\mathrm{O}_{2}$ fluxes, all for the same period of the first night (h 18 to h 32) of the deployment depicted in Figs. 2 and 3, calculated using instantaneous temperature corrected data (red bar), data without temperature correction (green bar), and "simulated" data produced from $8 \mathrm{~Hz}$ temperature recordings as shown in panel (a) and assuming a temperature coefficient of $3 \%$ (blue bar).

for the $\mathrm{O}_{2}$ and heat fluxes (Fig. 4) have the shape typically seen for shallow-water environments (Lorrai et al., 2010; Berg et al., 2013). The fact that all flux contributions for both the $\mathrm{O}_{2}$ and heat fluxes had frequencies lower than $\sim 0.9 \mathrm{~Hz}$, combined with the fast-responding dual $\mathrm{O}_{2}$-temperature sensor's response times $\left(t_{90} \%\right)$ of $0.51 \mathrm{~s}$ for $\mathrm{O}_{2}$ and $0.34 \mathrm{~s}$ for temperature (Berg et al., 2016), indicates that the entire flux signal over all frequencies was captured. Finally, for both $\mathrm{O}_{2}$ and temperature there was a clear relationship between the flux over the air-water interface (Figs. 2d, 3d) and the observed change in the water column (Figs. 2b, 3b). For $\mathrm{O}_{2}$, for example, the ratio between the averaged fluxes for the two nights (Fig. 2d; h 21 to h 30 vs. h 45 to h 54) equals 2.0, which is close to the ratio of 2.2 between the changes in water column concentrations (Fig. $2 b$ ) for the same two periods.

Both the $\mathrm{O}_{2}$ and temperature data (Figs. 2b, d, 3b, d) contained a clear diurnal signal overall. For $\mathrm{O}_{2}$, however, this was not driven by biological processes, i.e., net primary $\mathrm{O}_{2}$ production during daytime and respiration during nighttime, as this would have resulted in an increase in mean water column $\mathrm{O}_{2}$ concentration during daytime and a decrease at nighttime. The fact that the opposite pattern was found indicates that physical processes related to thermal conditions were controlling the $\mathrm{O}_{2}$ dynamics. Specifically, colder nighttime air temperatures and possibly also long-wave thermal radiation to the atmosphere were driving the substantial heat flux out of the river (Fig. 3d), which resulted in falling water temperatures (Fig. 3b). This, in turn, changed the $\mathrm{O}_{2}$ saturation concentration $\left(C_{\text {air }}\right.$ in Eq. 1$)$ and thus the driving concentration difference of $\mathrm{O}_{2}$ exchange over the air-water interface (Fig. 2b). During the daytime, the reverse pattern was in place. This rather complex relationship, or linkage via physical processes, is the only mechanism that can explain the overall pattern found for this deployment (Figs. 2, 3). Considering that these measurements were done under conditions that did not include any uncommon or extreme weather conditions suggests that physical processes, and not biological processes, are often an important, or even the main, driver of $\mathrm{O}_{2}$ dynamics in shallow-water rivers and streams. An unfortunate consequence of this dominance or control by physical conditions, which we believe is not yet fully recognized, is that it adds substantial uncertainty to the widely used approach of deriving metabolic estimates (e.g., gross primary production, respiration, net ecosystem metabolism) from time series of measured water column $\mathrm{O}_{2}$ concentrations (Odum, 1956; Hall et al., 2016).

The standard gas exchange coefficients $\left(k_{600}\right)$ for all of our four deployments (distributed on three different river sites, all with smooth quietly flowing water without standing riffles or waves; Fig. 1) did not show a significant relationship with river current velocity (Fig. 5; Table 1). This is in line with previously published results from across-site comparisons (Hall et al., 2016), but the substantial variation among $k_{600}$ values for some individual deployments (in particular for the Moormans River deployment; Fig. 2) despite only moderately varying river flow velocity and insignificant winds is surprising. For example, $k_{600}$ varied from a nearconstant value of $3.9 \mathrm{~m} \mathrm{~d}^{-1}$ during the first night (Fig. 2e; h 19 to h 32), followed by an almost 3 times smaller daytime value of $1.4 \mathrm{md}^{-1}$ (h33 to $\mathrm{h} 42$ ), and then increased again at the onset of the second night before finally tapering off to a small value of $0.9 \mathrm{md}^{-1}$ (h 52 to $\mathrm{h} 56$ ) at the end of the deployment. The co-variance of the heat exchange (Fig. 3d) suggests that turbulence, or turbulent-like motions (which stimulates gas exchange) was generated by natural convective forces driven by the substantial heat loss from the river during the nighttime (Fig. 3d). Conversely, during the daytime, when the heat flux was directed into the river (Fig. 3d), turbulent motions were presumably dampened by vertical temperature stratification in the surface water. Given the "low-energy" smooth and quietly flowing water, we find this explanation for the varying $k_{600}$ values (Fig. 2e) likely and note that this controlling factor has been described before (Bannerjee and MacIntyre, 2004; MacIntyre et al., 2010). We also note that this observed complex pattern illustrates the 
difficulties that can be associated with determining accurate air-water gas exchange rates and coefficients without direct site- and time-specific measurements.

An important methodological finding linked to the new approach is that $\mathrm{O}_{2}$ sensor readings should, at least in some cases, be corrected for temperature sensitivity using concurrent high-speed temperature readings as was done here for all $\mathrm{O}_{2}$ fluxes used to estimate air-water gas exchange coefficients (Fig. 2e; Table 1). In the benthic environment the vertical turbulent heat flux is usually small relative to the $\mathrm{O}_{2}$ flux due to slowly and modestly varying mean temperatures in the bottom water. However, results presented here show that rapid temperature fluctuations associated with the substantial turbulent heat flux below the air-water interface can mistakenly be recorded as fluctuations in the $\mathrm{O}_{2}$ concentration and bias the $\mathrm{O}_{2}$ flux calculation significantly if instantaneous temperature correction is omitted (Fig. 6). It is unclear how widespread this problem is - more studies are needed to determine that - but in the example included here, this bias alters the flux by more than a factor of 3 (Fig. 6b). Our data were recorded during winter and one could argue that the $\mathrm{O}_{2}$ exchange would be much larger during summer due to extensive primary production and respiration, which would reduce the relative magnitude of this bias. But as the $\mathrm{O}_{2}$ flux is indeed likely to be more pronounced during summer than during winter, so is the heat flux.

\section{Summary and recommendations}

Based on our proof-of-concept deployments, the aquatic eddy covariance technique applied right below the air-water interface should be particularly useful in detailed studies of gas exchange that evaluate its dynamics and controls. The approach can consequently help reduce the generally recognized problem of large uncertainties linked to gas exchange estimates in traditional aquatic ecosystem studies.

The floating platform we used here for measuring aquatic eddy covariance fluxes right below the air-water interface (Fig. 1) can easily be reproduced as it relies exclusively on standard materials and commercially available instrumentation, the latter designed with plug-and-play capabilities. Furthermore, standard software for eddy flux extractions developed for the benthic environment or for the atmospheric boundary layer can be used to estimate air-water fluxes.

We recommend that eddy covariance data are recorded close to the air-water interface (Fig. 1c) to minimize the effects of the $\mathrm{O}_{2}$ storage in the water between the measuring point and the surface and because gradients of both $\mathrm{O}_{2}$ and temperature can form in the upper water column. We also recommend that simultaneous high-speed temperature measurements are performed within a few millimeters of the $\mathrm{O}_{2}$ concentration recordings to allow for instantaneous temperature correction of the $\mathrm{O}_{2}$ signal (Fig. 6b).
Finally, our results illustrate that the $\mathrm{O}_{2}$ concentration difference driving the air-water gas exchange is often small (Fig. 2b), here less than $2 \%$ of the absolute concentration. This emphasizes the importance of relying both on accurately calibrated sensors to measure the water bulk concentration $\left(C_{\text {water }}\right.$ in Eq. 1) and precise determinations of the saturation concentration ( $C_{\text {air }}$ in Eq. 1$)$ that is corrected for temperature, salinity, and atmospheric pressure.

\section{Future work}

A further development of the new application of the aquatic eddy covariance technique presented here is to perform similar measurements from a moving platform in small lakes, reservoirs, and estuaries. In these environments, gas exchange and gas exchange coefficients are expected to vary spatially, for example from the lee to windward side of the aquatic system. By using a floating autonomously moving platform, we anticipate that such variations can be spatially mapped out and studied. We are currently performing the first tests along these lines.

Data availability. Data presented here can be acquired from the corresponding author.

Competing interests. The authors declare that they have no conflict of interest.

Acknowledgements. This study was supported by grants from the National Science Foundation (ESC-1550822, OCE-1334848) and the University of Virginia. We thank Julie and John Baird, Nancy and Ed Mcmurdo, Martha Hodgkins, and Brian Richter who allowed us to work on their beautiful properties in the Hardware River, the Mechums River, and the Moormans River. Finally, we thank Rachel E. Michaels for editorial assistance with the manuscript.

Edited by: Jack Middelburg

Reviewed by: two anonymous referees

\section{References}

Anderson, D. E., Striegl, R. G., Stannard, D. I., Michmerhuizen, C. M., McConnaughey, T. A., and LaBaugh, J. W.: Estimating lakeatmosphere $\mathrm{CO}_{2}$ exchange, Limnol. Oceanogr., 44, 988-1001, 1999.

Bannerjee, S. and MacIntyre, S.: The air-water interface: turbulence and scalar interchange, Adv. Coastal Ocean En., 9, 181237, 2004.

Bastviken, D., Tranvik, L. J., Downing, J. A., Crill, P. M., and Enrich-Prast, A.: Freshwater Methane Emissions Offset the Continental Carbon Sink, Science, 331, 50-50, 2011. 
Berg, P., Roy, H., Janssen, F., Meyer, V., Jorgensen, B. B., Huettel, M., and de Beer, D.: Oxygen uptake by aquatic sediments measured with a novel non-invasive eddy-correlation technique, Mar. Ecol.-Prog. Ser., 261, 75-83, 2003.

Berg, P., Roy, H., and Wiberg, P. L.: Eddy correlation flux measurements: The sediment surface area that contributes to the flux, Limnol. Oceanogr., 52, 1672-1684, 2007.

Berg, P., Glud, R. N., Hume, A., Stahl, H., Oguri, K., Meyer, V., and Kitazato, H.: Eddy correlation measurements of oxygen uptake in deep ocean sediments, Limnol. Oceanogr.-Meth., 7, 576-584, 2009.

Berg, P., Long, M. H., Huettel, M., Rheuban, J. E., McGlathery, K. J., Howarth, R. W., Foreman, K. H., Giblin, A. E., and Marino, R.: Eddy correlation measurements of oxygen fluxes in permeable sediments exposed to varying current flow and light, Limnol. Oceanogr., 58, 1329-1343, 2013.

Berg, P., Koopmans, D., Huettel, M., Li, H., Mori, K., and Wüest, A.: A new robust dual oxygen-temperature sensor for aquatic eddy covariance measurements, Limnol. Oceanogr., 14, 151167, 2016.

Berg, P., Delgard, M. L., Glud, R. N., Huettel, M., Reimers, C. E., and Pace, M. L.: Non-invasive Flux Measurements at the Benthic Interface: the Aquatic Eddy Covariance Technique, Limnol. Oceanogr.-Meth., 7, 1-50, https://doi.org/10.1002/loe2.10005, 2017.

Billett, M. and Moore, T.: Supersaturation and evasion of $\mathrm{CO}_{2}$ and $\mathrm{CH}_{4}$ in surface waters at Mer Bleue peatland, Canada, Hydrol. Process., 22, 2044-2054, 2008.

Borges, A. V., Delille, B., Schiettecatte, L. S., Gazeau, F., Abril, G., and Frankignoulle, M.: Gas transfer velocities of $\mathrm{CO}_{2}$ in three European estuaries (Randers Fjord, Scheldt, and Thames), Limnol. Oceanogr., 49, 1630-1641, 2004.

Butman, D. and Raymond, P. A.: Significant efflux of carbon dioxide from streams and rivers in the United States, Nat. Geosci., 4, 839-842, 2011.

Cole, J. J., Prairie, Y. T., Caraco, N. F., McDowell, W. H., Tranvik, L. J., Striegl, R. G., Duarte, C. M., Kortelainen, P., Downing, J. A., Middelburg, J. J., and Melack, J.: Plumbing the global carbon cycle: Integrating inland waters into the terrestrial carbon budget, Ecosystems, 10, 171-184, 2007.

Cole, J. J., Bade, D. L., Bastviken, D., Pace, M. L., and Van de Bogert, M.: Multiple approaches to estimating air-water gas exchange in small lakes, Limnol. Oceanogr.-Meth., 8, 285-293, 2010.

Fritzsche, E., Gruber, P., Schutting, S., Fischer, J. P., Strobl, M., Müller, J. D., Borisov, S. M., and Klimant, I.: Highly sensitive poisoning-resistant optical carbon dioxide sensors for environmental monitoring, Anal. Methods, 9, 55-65, 2017.

Garcia, H. E. and Gordon, L. I.: Oxygen solubility in seawater: Better fitting equations, Limnol. Oceanogr., 37, 1307-1312, 1992.

Genereux, D. P. and Hemond, H. F.: Determination of gas exchange rate constants for a small stream on Walker Branch Watershed, Tennessee, Water Resour. Res., 28, 2365-2374, 1992.

Gundersen, J. K., Ramsing, N. B., and Glud, R. N.: Predicting the signal of O-2 microsensors from physical dimensions, temperature, salinity, and O-2 concentration, Limnol. Oceanogr., 43, 1932-1937, 1998.
Hall, R. O., Tank, J. L., Baker, M. A., Rosi-Marshall, E. J., and Hotchkiss, E. R.: Metabolism, gas exchange, and carbon spiraling in rivers, Ecosystems, 19, 73-86, 2016.

Hanson, P. C., Pollard, A. I., Bade, D. L., Predick, K., Carpenter, S. R., and Foley, J. A.: A model of carbon evasion and sedimentation in temperate lakes, Glob. Change Biol., 10, 1285-1298, 2004.

Holst, G., Glud, R. N., Kuhl, M., and Klimant, I.: A Microoptode Array For Fine-Scale Measurement of Oxygen Distribution, Sensor. Actuat. B-Chem., 38, 122-129, 1997.

Holst, G., Kohls, O., Klimant, I., Konig, B., Kuhl, M., and Richter, T.: A modular luminescence lifetime imaging system for mapping oxygen distribution in biological samples, Sensor. Actuat. B-Chem., 51, 163-170, 1998.

Hume, A. C., Berg, P., and McGlathery, K. J.: Dissolved oxygen fluxes and ecosystem metabolism in an eelgrass (Zostera marina) meadow measured with the eddy correlation technique, Limnol. Oceanogr., 56, 86-96, 2011.

Jonsson, A., Åberg, J., Lindroth, A., and Jansson, M.: Gas transfer rate and $\mathrm{CO}_{2}$ flux between an unproductive lake and the atmosphere in northern Sweden, J. Geophys. Res.-Biogeo., 113, G04006, https://doi.org/10.1029/2008JG000688, 2008.

Klimant, I., Meyer, V., and Kuehl, M.: Fiber-optic oxygen microsensors, a new tool in aquatic biology, Limnol. Oceanogr., 40, 1159-1165, 1995.

Koopmans, D. J. and Berg, P.: Stream oxygen flux and metabolism determined with the open water and aquatic eddy covariance techniques, Limnol. Oceanogr., 60, 1344-1355, 2015.

Lee, X., Massman, W., and Law, B.: Handbook of micrometeorology: A guide for surface flux measurement and analysis, Kluwer Academic Publishers, 2004.

Liss, P. and Slater, P.: Flux of gases across the air-sea interface, Nature, 247, 181-184, 1974.

Long, M. H., Berg, P., de Beer, D., and Zieman, J. C.: In situ coral reef oxygen metabolism: An eddy correlation study, Plos One, 8, e58581, https://doi.org/10.1371/journal.pone.0058581, 2013.

Lorke, A., McGinnis, D. F., Maeck, A., and Fischer, H.: Effect of ship locking on sediment oxygen uptake in impounded rivers, Water Resour. Res., 48, W12514, https://doi.org/10.1029/2012WR012483, 2012.

Lorke, A., McGinnis, D. F., and Maeck, A.: Eddy-correlation measurements of benthic fluxes under complex flow conditions: Effects of coordinate transformations and averaging time scales, Limnol. Oceanogr.-Meth., 11, 425-437, 2013.

Lorrai, C., McGinnis, D. F., Berg, P., Brand, A., and Wüest, A.: Application of oxygen eddy correlation in aquatic systems, J. Atmos. Ocean. Tech., 27, 1533-1546, 2010.

MacIntyre, S., Wanninkhof, R., and Chanton, J. P.: Trace gas exchange across the air-water interface in freshwater and coastal marine environments, 52-97, in: Biogenic Trace Gases: Measuring Emissions from Soil and Water, edited by: Matson, R. C. H. P. A., Blackwell Science Ltd., New York, 1995.

MacIntyre, S., Jonsson, A., Jansson, M., Aberg, J., Turney, D. E., and Miller, S. D.: Buoyancy flux, turbulence, and the gas transfer coefficient in a stratified lake, Geophys. Res. Lett., 37, L24604, https://doi.org/10.1029/2010GL044164, 2010.

Mammarella, I., Nordbo, A., Rannik, Ü., Haapanala, S., Levula, J., Laakso, H., Ojala, A., Peltola, O., Heiskanen, J., Pumpanen, J., and Vesala, T.: Carbon dioxide and energy fluxes over a small 
boreal lake in Southern Finland, J. Geophys. Res.-Biogeo., 120, 1296-1314, 2015.

Marino, R. and Howarth, R. W.: Atmospheric oxygen-exchange in the Hudson River - Dome measurements and comparison with other natural-waters, Estuaries, 16, 433-445, 1993.

McKenna, S. and McGillis, W.: The role of free-surface turbulence and surfactants in air-water gas transfer, Int. J. Heat Mass Tran., 47, 539-553, 2004.

Odum, H. T.: Primary production in flowing waters, Limnol. Oceanogr., 1, 103-117, 1956.

Raymond, P. and Cole, J.: Gas exchange in rivers and estuaries: Choosing a gas transfer velocity, Estuaries, 24, 312-317, 2001.

Raymond, P. A., Zappa, C. J., Butman, D., Bott, T. L., Potter, J., Mulholland, P., Laursen, A. E., McDowell, W. H., and Newbold, D.: Scaling the gas transfer velocity and hydraulic geometry in streams and small rivers, Limnol. Oceanogr., 2, 41-53, 2012.

Raymond, P. A., Hartmann, J., Lauerwald, R., Sobek, S., McDonald, C., Hoover, M., Butman, D., Striegl, R., Mayorga, E., Humborg, C., Kortelainen, P., Durr, H., Meybeck, M., Ciais, P., and Guth, P.: Global carbon dioxide emissions from inland waters, Nature, 503, 355-359, 2013.

Rheuban, J. E. and Berg, P.: The effects of spatial and temporal variability at the sediment surface on aquatic eddy correlation flux measurements, Limnol. Oceanogr.-Meth., 11, 351-359, 2013.

Rheuban, J. E., Berg, P., and McGlathery, K. J.: Multiple timescale processes drive ecosystem metabolism in eelgrass (Zostera marina) meadows, Mar. Ecol.-Prog. Ser., 507, 1-13, 2014.
Rovelli, L., Attard, K. M., Bryant, L. D., Flögel, S., Stahl, H. J., Roberts, M., Linke, P., and Glud, R. N.: Benthic $\mathrm{O}_{2}$ uptake of two cold-water coral communities estimated with the non-invasive eddy-correlation technique, Mar. Ecol.-Prog. Ser., 525, 97-104, 2015.

Van de Bogert, M. C., Carpenter, S. R., Cole, J. J., and Pace, M. L.: Assessing pelagic and benthic metabolism using free water measurements, Limnol. Oceanogr.-Meth., 5, 145-155, 2007.

Van de Bogert, M. C., Bade, D. L., Carpenter, S. R., Cole, J. J., Pace, M. L., Hanson, P. C., and Langman, O. C.: Spatial heterogeneity affects estimates of ecosystem metabolism in two northern lakes, Limnol. Oceanogr., 57, 1689-1700, 2012.

Wanninkhof, R.: Kinetic fractionation of the carbon isotopes ${ }^{13} \mathrm{C}$ and ${ }^{12} \mathrm{C}$ during transfer of $\mathrm{CO}_{2}$ from air to seawater, Tellus $\mathrm{B}$, 37, 128-135, 1985.

Wanninkhof, R., Mulholland, P. J., and Elwood, J. W.: Gasexchange rates for a 1st-order stream determined with deliberate and natural tracers, Water Res. Res., 26, 1621-1630, 1990.

Watson, A. J., Upstill-Goddard, R. C., and Liss, P. S.: Air-sea gas exchange in rough and stormy seas measured by a dual-tracer technique, Nature, 349, 145-147, 1991.

Whitman, W. G.: The two film theory of gas absorption, Chemical and Metallurgical Engineering, 29, 146-148, 1923. 